\title{
Aspectos fisiopatológicos e assistenciais de enfermagem na reabilitação da pessoa com lesão medular
}

\author{
PHYSIOPATHOLOGICALASPECTS AND NURSING CARE ON REHABILITATION OF PATIENT \\ WITH SPINAL CORD INJURY
}

\section{ASPECTOS FISIOPATOLÓGICOS Y ASISTENCIALES DE ENFERMERÍA EN LAREHABILITACIÓN DE LA PERSONA CON LESIÓN MEDULAR}

\section{Denise Stela Bruni ${ }^{1}$, Kelly Cristina Strazzieri ${ }^{2}$, Marcella Nicoletti Gumieiro ${ }^{3}$, Romy Giovanazzi ${ }^{4}$, Vinício de Góes Sá ${ }^{5}$, Ana Cristina Mancussi e Faro ${ }^{6}$}

\begin{abstract}
RESUMO
$O$ traumatismo raquimedular é uma agressão à medula espinhal que pode ocasionar danos neurológicos, tais como alteração das funções motora, sensitiva e autônoma. Este artigo tem como propósito relatar detalhadamente as principais complicações clínicas resultantes desse tipo de lesão, e apresentar as intervenções assistenciais de enfermagem que possam auxiliar na promoção do bem estar e na melhoria da qualidade de vida dos pacientes, seja em caráter de acometimento já instalado ou profilático.
\end{abstract}

\section{PALAVRAS-CHAVE}

Traumatismos da medula espinhal.

Reabilitação.

Enfermagem.

\begin{abstract}
Spinal cord injury can cause neurological damage such as alterations in the motor, sensitive and autonomic function. In this paper, details of clinical complications such as PVT, infection, respiratory insufficiency, pressure ulcers, autossomic disreflection, orthostatic hypotension, sphincteral-vesical and intestinal disfunctions, are related. And will also present prophylactic and therapeutic nursing care interventions designed for the well-being and improvement in life quality for patients.
\end{abstract}

\section{KEYWORDS}

Spinal Cord Injury.

Rehabilitation.

Nursing.

\section{RESUMEN}

El traumatismo de la médula espinal puede llevar a daños neurológicos, incluso a la alteración de las funciones motora, sensorial y autonómica. En este trabajo nos proponemos descubrir detalladamente las más importantes complicaciones clínicas resultantes de ese tipo de lesión, y enseñar las intervenciones asistenciales de enfermería que puedan ayudar en la promoción del bienestar y en la mejora de la calidad de vida de los pacientes, sea en carácter de lesión ya instalada o en carácter profiláctico.

\section{PALABRAS CLAVE}

Lesión Medular.

Rehabilitación.

Enfermería.
1 Aluna do $4^{\circ}$ ano do Curso de Graduação em Enfermagem da Escola de Enfermagem da USP (EEUSP). denfe@bol.com.br

2 Aluna do $4^{\circ}$ ano do Curso de Graduação em Enfermagem da EEUSP.

strazzieri@ig.com.br

3 Aluna do $4^{\circ}$ ano do Curso de Graduação em Enfermagem da EEUSP.

manicoletti@hotmail.com

4 Aluna do $3^{\circ}$ ano do Curso de Graduação em Enfermagem da EEUSP.

romybelza@bol.com.br

5 Aluna do $3^{\circ}$ ano do Curso de Graduação em Enfermagem da EEUSP.

ivamy@uol.com.br

6 Professor Livre

Docente do

Departamento de Enfermagem MédicoCirúrgica da EEUSP. rafacris@usp.br 
Denise Stela Bruni Kelly Cristina Strazzieri Marcella Nicoletti Gumieiro Romy Giovanazzi Vinício de Góes Sá Ana Cristina M. e Faro

\section{INTRODUÇÃO}

O presente trabalho apresenta os aspetos fisiopatológicos e assistenciais desenvolvidos por um grupo de estudantes do Curso de Graduação em Enfermagem, durante o ensino-aprendizagem prático junto aos pacientes em fase aguda da lesão medular. Sua finalidade é divulgar parte do conhecimento apreendido pelos alunos sobre a Reabilitação em Enfermagem, especificamente em pessoas com múltiplas incapacidades, que, segundo a Organização Mundial de Saúde (OMS), traduz-se por restrições ou lacunas na performance de atividades próprias ao ser humano. Descrever as bases assistenciais dos cuidados de enfermagem apreendidos e implementados pelos alunos, orientados e supervisionados por uma docente de enfermagem, durante o ensino prático de campo da disciplina Enfermagem MédicoCirúrgica na Saúde do Adulto. O estudo fundamentou-se na coleta de dados de entrevista, exame físico e busca em prontuário de maneira sistemática com vistas à identificação de problemas. Com a análise das alterações e correlacionando-as com a fisiopatologia da lesão medular, buscou-se o planejamento da assistência e a sua implementação com a avaliação dos resultados durante todo o processo.

De acordo com Faro ${ }^{(1)}$, as expectativas de estudantes de enfermagem quanto ao ensino de Reabilitação, durante o curso de graduação, são positivas e apontam propostas para ampliar esta abordagem mesmo durante a hospitalização, ou seja, compreendê-la o mais precocemente possível.

\section{ASPECTOS FISIOPATOLÓGICOS EASSISTENCIAIS NOS DISTÚRBIOS NEUROLÓGICOS DECORRENTES DOTRAUMATISMORAQUIMEDULAR}

O trauma raquimedular (TRM) é uma agressão à medula espinhal que pode ocasionar danos neurológicos, tais como alterações da função motora, sensitiva e autônoma, ocorrendo predominantemente nos homens em idade produtiva (18-35 anos) ${ }^{(1)}$.

Metade dos traumatismos resultam de acidentes com veículos motorizados, quedas, acidentes de trabalho, esportivos (principalmente aquáticos), e outros decorrentes de ferimento por armas de fogo ${ }^{(2)}$.
A medula pode ser lesada por corpos estranhos ou por processos relacionados a uma vascularização deficiente, levando à isquemia, hipóxia, edema e causando danos à mielina e aos axônios ${ }^{(2)}$.

Freqüentemente, as vértebras mais envolvidas são a $5^{\mathrm{a}}$ e a $7^{\mathrm{a}}$ cervicais, a $12^{\mathrm{a}}$ torácica e a $1^{\mathrm{a}}$ lombar. Tais vértebras são as mais suscetíveis pois há uma grande faixa de mobilidade nestas áreas da coluna ${ }^{(2)}$.

$\mathrm{O}$ dano à medula espinhal varia de uma concussão transitória, da qual o paciente recupera-se completamente (contusão, laceração e compressão da substância da medula) até uma transecção completa da mesma, tornando o paciente paralisado abaixo do nível da lesão traumática ${ }^{(2-3)}$.

Sendo assim, a lesão pode ser:

- Lesão completa - as funções motora e sensitiva estão ausentes abaixo dos 3 segmentos caudais consecutivos ao nível da lesão;

- Incompleta sensitiva - a atividade motora está presente e permanece certa sensibilidade;

- Incompleta motora não funcional - a função motora está ausente ou com o mínimo uso funcional;

- Incompleta motora funcional - a função motora está preservada e há funcionalidade abaixo do nível da lesão ${ }^{(1,4)}$.

O TRM envolve uma série de complicações, dentre elas o choque medular, que representa uma repentina perda da atividade reflexa na medula espinhal (arreflexia) abaixo do nível do trauma. Nesta condição os músculos enervados pela parte do segmento da medula situada abaixo do nível da lesão ficam completamente paralisados e flácidos e os reflexos são ausentes. A pressão arterial cai e as partes do corpo abaixo do nível da lesão ficam paralisadas e sem sensibilidade ${ }^{(2-3)}$.

Com os traumatismos cervicais de coluna torácica superior, a enervação para os principais músculos acessórios da respiração é perdida acarretando nos seguintes problemas respiratórios: redução da capacidade vital, retenção de secreções, aumento da pressão parcial de $\mathrm{CO}_{2}$, redução da $\mathrm{pO}_{2}$, insuficiência respiratória e edema pulmonar. Os reflexos desencadeantes das 
funções vesical e intestinal são afetados ocasionando ileoparalítico, priapismo, retenção urinária, alterações digestórias (dilatação gástrica), alterações cardiocirculatórias (hipotensão, bradicardia) e oscilações térmicas ${ }^{(3-4)}$.

O choque medular é parte, se não o todo, do acometimento da lesão medular. Ele desencadeia os efeitos "anormais e incorretos" do organismo/metabolismo do paciente, implicando em ações de enfermagem que promovam a manutenção ou o reestabelecimento da saúde, visando a melhoria da qualidade de vida ${ }^{(4-5)}$

A partir dos efeitos do choque medular, descritos acima, a assistência de enfermagem será fundamentada nas alterações decorrentes, sejam elas transitórias ou permanentes.

Frente ao exposto, podemos afirmar que a pessoa com lesão medular apresenta múltiplas incapacidades e, com isso, requer cuidados complexos pertinentes a tantas alterações. À seguir pontuamos as principais alterações encontradas durante a nossa experiência no campo prático, bem como a assistência proposta.

\section{Trombose Venosa Profunda (TVP)}

A TVP é uma complicação decorrente da imobilidade comum em pacientes com TRM. Aqueles que a desenvolvem estão sob risco de embolia pulmonar. A presença de TVP é avaliada através da mensuração da panturrilha e constatada caso haja aumento significativo na circunferência deste segmento ${ }^{(2)}$.

A terapia com doses baixas de anticoagulantes é iniciada para evitar a TVP e a embolia pulmonar; é indicado o uso de meias elásticas, a execução de exercícios fisioterápicos que promovam amplitude de movimento, uma hidratação adequada e a anulação de estímulos báricos externos nos membros inferiores decorrentes da flexão dos joelhos enquanto o paciente está acamado ${ }^{(2,6)}$.

Os cuidados de enfermagem ao paciente com TVP devem ser formulados considerandose a ausência do reflexo motor e a imobilidade que o paciente tetraplégico ou paraplégico apresenta, ou seja, posicionamento adequado no leito, com ligeira elevação, bem como movimentação passiva.

\section{Insuficiência Respiratória}

Os problemas respiratórios estão relacionados com o comprometimento da função pulmonar cuja gravidade depende do nível da lesão. Os músculos que contribuem com a respiração são os abdominais-intercostais, enervados por T1 a T11, e o diafragma enervado pelo nervo frênico do plexo cervical com raízes de $\mathrm{C} 3$ a C5. Por isso, no traumatismo da coluna cervical alta, a insuficiência respiratória aguda é a causa mais comum de morte ${ }^{(2)}$.

O padrão respiratório deve ser observado, a tosse avaliada e os pulmões auscultados, pois a paralisia dos músculos acessórios do pescoço, abdominais e da parede torácica e diafragma reduz o reflexo tussígeno e dificulta a eliminação das secreções brônquicas e faríngeas (principalmente em lesão de T1/T6). A possível insuficiência respiratória iminente é detectada pela observação do paciente, mensuração da capacidade vital e monitorização dos valores da gasometria arterial. A aspiração pode ser indicada, contudo deve ser utilizada com precaução pois pode estimular o nervo vago, produzindo bradicardia ${ }^{(2)}$.

A monitorização constante pela equipe de enfermagem deve ser precoce e necessária tanto na fase aguda quanto na crônica. A enfermagem, ao avaliar o padrão respiratório do paciente, deve proceder a ausculta pulmonar, investigar alterações instaladas considerando os hábitos pré-existentes ${ }^{(1)}$.

Caso o paciente não consiga tossir efetivamente devido à redução do volume inspiratório e a incapacidade para desenvolver pressão expiratória suficiente, a fisioterapia torácica e a tosse assistida podem ser indicadas. É importante assegurar a umidificação e a hidratação para prevenir que as secreções se tornem espessas e de difícil remoção mesmo com a tosse. $\mathrm{O}$ posicionamento adequado no leito, a mudança de decúbito e a tapotagem melhoram o desconforto ${ }^{(2)}$.

Para tratamento de pacientes com afecções crônicas, incapacitantes como a lesão, são encorajadas a vacina pneumocóccica e contra influenza ${ }^{(2)}$.

\section{Úlcera de Pressão (UP)}

Como o paciente com TRM fica imobilizado e apresenta incontinência urinária e fecal, perda de sensibilidade, alterações no turgor e na elasticidade da pele e circulatórias, 
Denise Stela Bruni Kelly Cristina Strazzieri Marcella Nicoletti Gumieiro Romy Giovanazzi Vinício de Góes Sá Ana Cristina M. e Faro

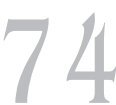

Rev Esc Enferm USP 2004; 38(1): 71-9. a ameaça para desenvolver UP é constante. Nas áreas de isquemia tecidual local em que há pressão contínua e na qual a circulação periférica é inadequada, as UP desenvolvemse dentro de 6 horas. Os sítios mais comuns localizam-se acima da tuberosidade isquiática, na região sacra, na trocantérica, nos calcanhares e nos cotovelos $(2,7)$

De acordo com a profundidade e a extensão das feridas, podemos classificá-las desta forma: grau 1, eritema na pele intacta; grau 2, úlceração superficial com perda da camada epidérmica e derme, sem atingir o subcutâneo (é o caso das bolhas); grau 3, danos ao nível da epiderme, derme e subcutâneo com proximidade da fáscia muscular que, embora possa estar exposta, ainda não foi atingida; grau 4, extensiva destruição com necrose de tecido, danos em estruturas musculares, tendões, ossos e até cápsula sinovial. É possível a presença de infecção local e exsudato (assim como nos outros níveis) e o paciente corre grave risco de evoluir para septicemia ${ }^{(1)}$.

Compete ao enfermeiro propor condutas no sentido de orientar e treinar o paciente/família/ cuidador quanto às mudanças de decúbito minimamente a cada duas horas nas posições dorsal e laterais (direita -esquerda). $\mathrm{O}$ decúbito ventral pode ser indicado para paraplégicos somente quando há impossibilidade de usar os laterais e/ou dorsal ${ }^{(1,7)}$.

A inspeção cuidadosa da pele deve ser feita em todas as mudanças de decúbito, mantendo sempre leito e períneo livres de sujidades. No banho o paciente deve utilizar sabonete neutro e sua pele deve ser enxaguada e seca delicadamente, não friccionando a toalha contra a pele. Áreas sensíveis à pressão devem ser mantidas bem lubrificadas e hidratadas pelo uso diário de creme umectante ${ }^{(2,7)}$.

Podem ser colocadas espumas nas formas de cilindros, quadrados, retângulos e triângulos para oferecer apoio e sustentação às regiões dorsal, poplítea, dos cotovelos e calcanhares. $\mathrm{Na}$ região sacral tem-se preconizado o uso de almofadas d'água quadradas e de espuma siliconizada em diferentes densidades ${ }^{(1,7)}$.

O paciente é orientado e esclarecido quanto ao desenvolvimento das UP nas proeminências ósseas expostas à pressão contínua e prolongada. Pacientes paraplégicos são incentivados a usar espelhos para a inspeção destas áreas duas vezes ao dia, observando a presença de eritema, edema ou escoriações. As superfícies em contato com o corpo, como lençóis e colchões, devem ser macias, e estar bem posicionadas, evitando assim ondulações que possam traumatizar a pele do paciente ${ }^{(1,7)}$

A ausência de sensibilidade exige cuidados como nutrição equilibrada, hidratação cutânea e posicionamento correto seja no leito ou em cadeira de rodas ${ }^{(1)}$.

Uma vez instalada a úlcera, o tratamento deve ser realizado por meio de curativos diários, alívio total da pressão sobre a área e desbridamento das regiões necrosadas. Aconselha-se recorrer a um profissional qualificado, como o enfermeiro, que avalie e cuide corretamente do ferimento ${ }^{(1,8)}$.

\section{Disreflexia Autonômica}

É uma emergência aguda que ocorre em pacientes com lesão medular como resultado de respostas autônomas acentuadas aos estímulos que são inócuos em indivíduos normais. Essa síndrome é caracterizada por cefaléia intensa, hipertensão paroxística, pupilas dilatadas, visão embaçada, piloereção, sudorese profusa, congestão nasal e bradicardia. Acontece comumente em pacientes com lesão medular acima do nível T6 ${ }^{(2)}$.

Inúmeros estímulos podem desencadear este reflexo como a distensão vesical (a causa mais comum), estimulação da pele(tátil, dolorosa, térmica), distensão de órgãos viscerais, especialmente intestino (devido a constipação e impactação) e unhas encravadas. Ocorre vários meses depois do trauma tendo maior incidência em tetraplégicos, desaparecendo dentro de 3 meses após o trauma ${ }^{(2)}$.

Como inúmeros estímulos podem desencadear tais reflexos, foram selecionadas intervenções de enfermagem de urgência. São elas:

- colocar imediatamente o paciente sentado;

- registrar pulso e pressão arterial para avaliar a eficácia das intervenções;

- esvaziar imediatamente a bexiga através de sondagem de alívio;

- promover lavagem intestinal ou fleetenema, considerando uma possível constipação como causa do evento; 
- eliminar qualquer outro estímulo que possa se constituir num evento desencadeador, como objetos injuriando a pele ou uma corrente de ar frio, bem como roupas e calçados apertados;

- administrar o tratamento medicamentoso (alfa e beta bloqueador e miorrelaxante) conforme prescrição médica ${ }^{(2)}$.

\section{Infecções}

Os pacientes tetraplégicos e paraplégicos estão mais predispostos à infecção e "sepsis", decorrentes de uma variedade de fontes. Por exemplo, o trato urinário, devido ao funcionamento anormal da bexiga e a constante manipulação -cateterismos-, apresenta episódios de distensão vesical e alteração das características da urina, com aspecto turvo devido aos sedimentos provocados pela infecção. No trato respiratório, o comprometimento do mecanismo da tosse, passível de estar ausente, contribui para a freqüente ocorrência de pneumonia; doenças intra abdominais podem estar presentes sem sintomas ou sinais localizados, por exemplo, na pancreatite o exame físico revela aumento da espasticidade e defesa abdominal; áreas de úlceras por pressão apresentam riscos para tornarem-se infectadas causando osteomielite e febre pela própria integridade tissular prejudicada, exposição ambiental e déficits nutricionais ${ }^{(2)}$.

A intervenção de enfermagem na prevenção da infecção e da sepsis é essencial para reduzir a morbimortalidade, manter a integridade da pele e reeducar a bexiga e o intestino, corrigindo a inconti-nência urinária e fecal. É essencial o acompanhamento da temperatura corporal e seu registro ${ }^{(2)}$.

O risco de infecção respiratória, sobretudo em tetraplégicos, pode diminuir quando:

- evita-se o contato entre pessoas com sintomas de infecção respiratória;

- estimula-se a tosse e a prática de exercícios respiratórios que ajudam a evitar o acúmulo de secreções;

- orienta-se quanto à mudança de decúbito;

- administra-se anualmente vacinas profiláticas contra a influenza;

- desestimula-se o tabagismo, para quem tem esse hábito;
- na traqueostomia, aspira-se adequadamente as vias aéreas;

- proporciona-se hidratação adequada com o intuito de fluidificar secreções ${ }^{(2)}$.

O risco de infecções do trato urinário são minimizadas ou prevenidas por:

- uso da técnica asséptica no manuseio do catéter;

- hidratação adequada;

- programa de treinamento vesical;

- prevenção de superdistensão vesical e estase ${ }^{(2)}$.

A infecção pelo rompimento da integridade da pele é evitada pela (o):

- periodicidade na mudança de decúbito;

- posicionamento adequado e conforto, tanto no leito como em cadeira de rodas;

- avaliação regular de todas as áreas do corpo, se possível utilizando um espelho para melhor visualização da pele;

- cuidado regular com a limpeza e lubrificação da pele;

- alívio da pressão, particularmente sobre áreas fissuradas da pele, proeminências ósseas e calcanhares;

- lençol sem dobras ou rugas ${ }^{(2)}$.

\section{Bexiga Neurogênica (disfunção vésico-esfincteriana)}

A bexiga é controlada por mecanismos voluntários e involuntários, e, imediatamente após um trauma medular, torna-se atônica e não pode contrair-se pela atividade reflexa. A retenção urinária é o resultado imediato da lesão medular. Como o paciente não sente a distensão vesical, o superestiramento da bexiga e do músculo detrusor pode ocorrer e retardar o retorno da função vesical. Qualquer lesão nervosa que interfira neste mecanismo origina uma bexiga neurogênica ${ }^{(2)}$.

Já quando a lesão do centro miccional (ao nível das raízes $\mathrm{S} 2, \mathrm{~S} 3$ e $\mathrm{S} 4$ que correspondem às vértebras $\mathrm{T} 11$ e T12) isola a bexiga da medula, o paciente pode referir vontade de urinar, mas não há esvaziamento vesical. Caso faça algum esforço, é possível que ocorra a drenagem de urina da bexiga autônoma ${ }^{(1)}$.

O esvaziamento vesical pode ser feito por meio do cateterismo intermitente, a cada 4 ou
Aspectos

fisiopatológicos e

assistenciais de

enfermagem na

reabilitação da

pessoa com

lesão medular

\section{政}


Denise Stela Bruni Kelly Cristina Strazzieri Marcella Nicoletti Gumieiro Romy Giovanazzi Vinício de Góes Sá Ana Cristina M. e Faro
6 horas, de acordo com o balanço hídrico do paciente para evitar o superestiramento da bexiga e a infecção do trato urinário ${ }^{(2)}$.

O volume urinário em cada esvaziamento não deve ultrapassar $500 \mathrm{ml}$. Na impossibilidade de se realizar o cateterismo intermitente utilizam-se sondas de demora que devem ser fixadas de modo a não originar fístulas. A sonda deve ser aberta a cada 3 ou 4 horas e trocada semanalmente ${ }^{(4)}$.

Ao paciente/família/cuidador incentiva-se o registro da ingesta hídrica, do padrão miccional, da quantidade, do aspecto da urina e também de quaisquer sensações sistêmicas incomuns que estiverem ocorrendo ${ }^{(1-2)}$.

Pode requerer para seu esvaziamento, a utilização de manobras específicas não invasivas, como a estimulação suprapúbica (estimulação digital por leves toques com as pontas dos dedos na região suprapúbica), Credê (compressão em baixo ventre com a mão espalmada ou fechada), Valsalva (inspiração profunda seguida de expiração forçada, o que aumenta a pressão intrabdominal), de acordo com a presença ou ausência de atividade vesical reflexa. É bom lembrar que tais estímulos sensitivos induzem ao esvaziamento vesical incompleto e sem o controle do paciente ${ }^{(1-2,6)}$.

Para a reeducação vesical, o hábito de ingerir 2 a 3 litros de líquido por dia aumenta o débito urinário e contribui para a prevenção de infecções do trato urinário. Antes de dormir e uma hora após cada refeição (café da manhã, almoço ou jantar), o esvaziamento da bexiga deve ser viabilizado com o auxílio das manobras de Credê, Valsalva e pela estimulação suprapúbica ${ }^{(9)}$.

A lavagem das mãos, com água abundante e sabão, quando for realizado o cateterismo, é fundamental ${ }^{(2)}$.

O autocateterismo vesical intermitente, técnica limpa apresenta muitas vantagens no tratamento das disfunções vesico-esfincterianas, já constatadas por pesquisas nacionais/ internacionais. É um procedimento considerado de fácil execução, que mais se aproxima da função vesical normal, reduz episódios de infecção urinária, preserva a função renal e promove a reeducação vesical ${ }^{(10-13)}$

\section{Disfunção Intestinal}

Devido à interrupção dos nervos da medula espinhal, as mensagens advindas da porção retal para o cérebro não conseguem passar pelo bloqueio na altura da lesão, o que pode resultar em movimentação intestinal insuficiente e acarretar constipação e impactação fecal. Os efeitos da imobilidade dessa musculatura variam dependendo do nível e da extensão da lesão. O mecanismo de esvaziamento intestinal é coordenado pelo nível medular S2 a S4 e a lesão a este nível deve incapacitar o desenvolvimento da defecação automática ${ }^{(1,9)}$.

As lesões acima de S2, muito mais comuns, capacitam a pessoa a desenvolver uma defecação reflexa ${ }^{(1,9)}$.

É importante investigar os hábitos alimentares e o padrão de eliminação intestinal anterior à lesão medular, bem como a situação atual, considerando e avaliandose a presença de ruídos hidroaéreos ${ }^{(9,14)}$.

Recomenda-se uma alimentação balanceada e uma hidratação adequada. Três refeições por dia (café da manhã/almoço/ jantar) são recomendadas para que se tenha massa fecal suficientemente volumosa. A ingesta hídrica (aproximadamente de 2,5 a 3 litros) torna menos consistente o bolo fecal facilitando sua eliminação. Quando ocorre constipação, deve-se ingerir mais líquidos, o que não se restringe somente à água mas também sucos de frutas, vitaminas, leite e iogurtes. Deve-se evitar chás e refrigerantes porque são constipantes e provocam flatulência ${ }^{(9,14)}$.

Alimentos com fibras como quiabo, abóbora, beterraba, laranja, mamão, pêra, melão, ameixa preta seca, figo, milho, frutas com casca, cereais integrais, pão preto, farelo de trigo, e iogurtes devem ser incentivados pois, por conterem maior quantidade de fibras, evitam a constipação e a flatulência. Alimentos como queijos, compota de maçã, pão branco, suco de maçã e cenoura, banana prata, coca-cola, gelatina, massas em geral, arroz, batata, carnes magras, feijão e repolho, devem ser ingeridos com moderação pois provocam constipação ${ }^{(9,14)}$.

É recomendável que o paciente padronize seu horário para a evacuação considerando os hábitos e horários anteriores à lesão medular, e, dessa forma, estabeleça uma rotina ${ }^{(9,14)}$.

Pode-se utilizar o artifício das manobras anteriormente citadas, acrescentando-se a de Rosing que é a massagem feita várias vezes 
no abdômen, no sentido da direita para a esquerda e de baixo para cima com leve compressão durante 20 a 30 minutos após as refeições ${ }^{(1,9,14)}$.

Durante as manobras, o paciente é orientado a adotar a posição sentada, e caso o equilíbrio permita, deve ficar inclinado para a frente. Para a prevenção de lesões cutâneas pode se adaptar espumas no assento sanitário e, por isso, é aconselhável evitar comadres e urinol. Caso as manobras não funcionem, está indicada a estimulação retal: introduz-se o dedo, se possível enluvado e lubrificado, suavemente no ânus com movimentos de "vaivém" durante 5 minutos. Caso não haja êxito com a prática, recomenda-se o supositório de glicerina. É aconselhável procurar assistência médica se não houver episódios de eliminação fecal por mais de três dias. O uso de laxantes sem orientação médica é desaconselhável. O enfermeiro/paciente/ cuidador deve observar e anotar sempre o aspecto (cor, odor) e o volume aproximado das fezes, considerando-se também o aspecto do abdomen ${ }^{(9,14)}$.

\section{Hipotensão Ortostática}

Em lesões medulares altas, acima de T6, ocorre a hipotensão ortostática devido a privação da resposta simpática responsável por manter o turgor tecidual e não permitir acúmulo de sangue nas paredes dos vasos sangüíneos. Esta situação é caracterizada por náuseas, síncope, tontura e incapacidade de tolerar a posição supina (principalmente em tetraplégicos). Tal quadro é agravado pelo déficit do retorno venoso e pela deficiência da mecânica ventilatória ${ }^{(9)}$.

Lesões de nível alto rompem com conexões simpáticas entre o tronco cerebral e o coração e podem ocasionar freqüência cardíaca relativamente baixa. Alterações dramáticas no pulso e na pressão arterial ocorrem em pacientes com TRM alto e não necessariamente produzem sintomas clínicos. Há também hipotensão sintomática relacionada a alterações posturais como nas mudanças de decúbito e de alimentação (resultante de um pool sangüíneo em membros inferiores e vasoconstrição ineficaz devido a lesão no sistema nervoso central) ${ }^{(2)}$.

Inúmeras técnicas podem ser usadas pela enfermagem para reduzir a freqüência dos episódios hipotensivos. A monitorização restrita dos sinais vitais antes e no decorrer da mudança de posição é uma delas. A elevação lenta da cabeceira da cama, na manhã anterior ao paciente ser removido para a posição sentada, associada ao uso de meias elásticas de alta compressão e faixas abdominais, quando se inicia o ortostatismo, possibilita prevenir a manifestação dessas crises por melhorar principalmente o retorno venoso dos membros inferiores. A medicação vasopressora utilizada para tratar a vasodilatação profunda, e a adoção do decúbito dorsal, mantendo os 4 membros elevados, são medidas terapêuticas na vigência aguda da hipotensão ortostática ${ }^{(2,5)}$.

Cada atividade deve ser planejada com antecedência e tempo adequados para o paciente mudar, lenta e progressivamente, da posição de decúbito dorsal para a posição sentada, e, depois, ereta ${ }^{(2)}$, ou seja, a cabeça e o tronco são elevados progressivamente até que, sentado, seja na cama ou em cadeira de rodas, fazendo ângulo de $90^{\circ}$ entre tronco e quadril, apresente equilíbrio e bem estar geral.

\section{Alterações psicossociais}

Em geral, leva tempo para o paciente e a família compreenderem a magnitude das incapacidades resultantes do TRM. Eles podem atravessar estágios de ajuste, incluindo choque, descrença, negação, depressão, luto e aceitação. Durante a fase aguda do trauma, a negação pode ser um mecanismo protetor de defesa dos pacientes, ajudando-os a superar a realidade do acontecimento. À medida que eles consci-entizamse do agravo, o processo de luto pode prolongar-se e tudo se fecha, uma vez que eles passam a reconhecer as metas de longo alcance e as expectativas podem ser interrompidas ou alteradas permanentemente. O período de depressão com freqüência continua à medida que o paciente apresenta perda de auto-estima em áreas de identidade própria e de papéis sociais e emocionais ${ }^{(2)}$.

$\mathrm{O}$ ajustamento à incapacidade tende ao desenvolvimento de metas realistas para o futuro, melhorando as habilidades que permanecem intactas e reinvestindo em outras atividades e relacionamentos. A rejeição à incapacidade causa negligência auto-destrutiva e não adesão ao programa terapêutico, que leva a mais frustração e depressão ${ }^{(2)}$.
Aspectos fisiopatológicos e assistenciais de enfermagem na reabilitação da pessoa com lesão medular 
Denise Stela Bruni Kelly Cristina Strazzieri Marcella Nicoletti Gumieiro Romy Giovanazzi Vinício de Góes Sá Ana Cristina M. e Faro
A exploração e a avaliação destes aspectos ajudam no desenvolvimento de um plano de cuidados significativo para a enfermagem, como por exemplo, arrumar meios para que sejam capazes de trabalhar e superar esta depressão, os pacientes devem ter, de alguma forma, esperança de alívio futuro. Portanto, eles devem ser orientados no sentido de adquirir auto-confiança em suas capacidades para que o auto-cuidado e a independência relativa sejam metas atingidas ${ }^{(2)}$.

Neste processo, entendido por Reabilitação, os cuidados físicos serão os primeiros a serem assimilados, enquanto os de ajustamento deverão ser contínuos por toda a vida ${ }^{(1)}$.

\section{PERSPECTIVAS PARAA ASSISTÊNCIA DOMICILIÁRIA}

As pessoas com lesão medular apresentam riscos para o desenvolvimento de complicações por toda a vida. As infecções do trato urinário, as úlceras de pressão e a espasticidade muscular podem aparecer necessitando até mesmo de hospitalização.

Para evitar essas complicações ou o agravamento das incapacidades, pacientes e familiares cuidadores têm de ser orientados sobre os cuidados com a pele, com o catéter vesical, sobre os exercícios de amplitude de movimento e outros cuidados já na admissão hospitalar.

O ensino sobre o autocuidado é reforçado durante as visitas domiciliárias pela Enfermeira de Reabilitação e conhecedora, portanto, da complexidade das alterações oriundas da lesão medular.

Podem ser recomendadas modificações no domicílio para facilitar o acesso e cuidados a serem realizados em casa. Materiais e equipamentos específicos também necessitam de prescrição médica e de enfermagem tanto para a aquisição como para a sua utilização.

\section{CONSIDERAÇÕES FINAIS}

A possibilidade de descrever a assistência de enfermagem implementada por um grupo de estudantes de enfermagem, baseada nos aspectos fisiopatológicos da lesão medular e em discussões diárias com a docente responsável pela supervisão do ensino prático no campo, foram fatores essenciais para a desmistificação da possibilidade de "cura" real, principalmente, para alunos de graduação em enfermagem. Parte desta utopia é proveniente não só da falta de conhecimento, mas também da esperança dos pacientes em relação à sua recuperação, notável a cada evolução de enfermagem e intervenções realizadas.

As intervenções de enfermagem aqui apresentadas e sugeridas não trazem de volta os movimentos perdidos, mas permitem a convivência com a incapacidade de maneira digna e com melhor qualidade de vida ${ }^{(5)}$.

Em casos de TRM, devemos considerar que a Reabilitação tenha início no momento do acidente, pois envolve a aprendizagem do paciente e da família diante de uma vida completamente diferente. À partir daí, o maior desafio é a prevenção das complicações ou de incapacidades secundárias que, se contornadas, melhoram gradativamente o potencial funcional dos pacientes.

Para superar o impacto de uma vida limitante, porém atuante, familiares e/ou cuidadores deverão ressaltar aspectos positivos da recuperação, incentivando e elogiando os progressos fisioterapêuticos, assim como respeitando os momentos de desesperança, frustração e hostilidade, uma vez que também pertencem às fases de ajustamento de uma nova condição de vida.

\section{REFERÊNCIAS}

(1) Faro ACM. Assistência de enfermagem ao paciente com traumatismo raquimedular. In: Ventura MF, Faro ACM, Onoe EKN, Utimura M. Enfermagem ortopédica. São Paulo: Ícone; 1996. p.175-89.

(2) Smeltzer SC, Bare BG. Brunner \& Suddarth: tratado de enfermagem médico-cirúrgica. $7^{\mathrm{a}} \mathrm{ed}$. Rio de Janeiro: Guanabara Koogan; 1994. 4v.
(3) Greve JMDA. Reabilitação da lesão da medula espinal. In: Nitrini R. A neurologia que todo médico deve saber. São Paulo: Maltese/Santos; 1991.

(4) Porto CC. Exame clínico: bases para a prática médica. Rio de Janeiro: Guanabara Koogan; 2000. 
(5) Doenges ME. Diagnóstico e intervenção de enfermagem. $5^{\text {a }}$ ed. Porto Alegre: Artemed; 1999.

(6) Greve JMDA. Fundamentos clínicos do tratamento de reabilitação na lesão medular. Âmb Hosp 1994;6(67):55-74.

(7) Faro ACM. Fatores de risco para úlcera de pressão: subsídios para a prevenção. Rev Esc Enferm USP 1999; 33(3): 279-83.

(8) Farias MA. Técnicas de curativos em ortopedia. Rev Enferm Compl HCFMUSP 1998; 2(2): 21-3.

(9) Tonello AS. Aspectos da reeducação intestinal em lesados medulares. [dissertação]. São Paulo (SP): Escola Paulista de Medicina da UNIFESP; 1999.

(10) Lelis MAS. Cateterismo vesical intermitente - técnica limpa: caracterização da prática vivenciada por um grupo de pacientes. [tese] São Paulo (SP): Escola de Enfermagem da USP; 1998.
(11)Lapides J. Clean, intermittent self-catheterization in the treatment of urinary tract disease. J Urol 1972; 107(3):458-61.

(12) Faro ACM. Do diagnóstico à conduta de enfermagem: a trajetória do cuidar na reabilitação do lesado medular. [dissertação]. São Paulo (SP): Escola de Enfermagem da USP; 1995.

(13) Moroóka M. Autocateterismo vesical intermitente técnica limpa: descrição do procedimento realizado pelos pacientes com lesão medular. [tese] São Paulo (SP): Escola de Enfermagem da USP; 2000.

(14) Centro de Vida Independente do Rio de Janeiro. Programa de reeducação intestinal após lesão raquimedular. Rio de Janeiro; [s.d.].
Aspectos

fisiopatológicos e assistenciais de enfermagem na reabilitação da pessoa com lesão medular 